\title{
促进绿色制造技术扩散的政策模式创新研究
}

\author{
刘朋 $^{1,2}$, 周可迪 ${ }^{1}$, 延建林 $^{1}$, 周源 ${ }^{2}$, 薛澜 $^{2}$ \\ （1. 中国工程院战略咨询中心，北京 $100088 ； 2$. 清华大学公共管理学院，北京 100084）
}

摘要：本文旨在探索中国促进绿色制造技术扩散的治理模式和政策工具，探讨完善节能治理模式的新方向。首先，通过文献 综述揭示绿色制造技术扩散的障碍, 并以全国电机能效提升计划为例, 总结各地方政府推广绿色技术的典型政策和措施。采 用案例研究方法, 分析东莞市针对万台注塑机电机节能改造所面临的困难而采取组合政策和措施, 特别是为推动合同能源管 理而创新的金融模式。最后, 分析了新模式克服绿色技术扩散障碍, 达到示范推广效果。其政策体系和新模式将有助于促进 战略性新兴产业中节能环保产业的发展。

关键词: 绿色制造; 节能减排; 模式创新

中图分类号: TH16; X22 文献标识码: A

\section{Promoting Green Manufacturing Technology Diffusion Using Innovative Policy Implementation Methods}

\author{
Liu Peng ${ }^{1,2}$, Dillon K. Zhou ${ }^{1}$, Yan Jianlin ${ }^{1}$, Zhou Yuan², Xue Lan ${ }^{2}$ \\ (1. The CAE Centre for Strategic Studies, Beijing 100088, China; 2. School of Public Policy and Management, \\ Tsinghua University, Beijing 100084, China)
}

\begin{abstract}
This paper presents initial findings on a current approach in public policy to promote green technology diffusion using innovative policy measures, through the case of the electric motor upgrading project (EMUP), and examines the degree of success of local governments in their effort to encourage the adoption of high efficiency motors (HEMs). The barriers to green technology diffusion are explored to showcase the challenges faced by local implementer. This research demonstrates the successes of various regions with an emphasis on Dongguan City, which has enjoyed great success using subsidies and financial tools to promote the use of energy performance contracts as an innovative financing mode. Finally, this article analyzes the methods and outcomes of the EMUP, thus far, in order to explain the reasons behind the success of this initial phase of implementation. Further research will be needed to monitor the progress of this initiative. This article summarizes the policy system and the new model will help to promote the development of energy conservation and environmental protection industry in the strategic emerging industries.
\end{abstract}

Key words: green manufacturing; energy saving and emission reduction; innovative mode

\section{一、前言}

改革开放以来，中国经济社会发展取得举世瞩
目的成就。然而, 经济高速增长的同时, 不能以牺 牲资源和破坏环境为代价。中国的能源、环境已经 没有太多的发展空间，但还要继续发展，所以必须

收稿日期 : 2016-05-12; 修回日期 : 2016-06-27

作者简介: 刘朋, 中国工程院, 清华大学, 博士后, 研究方向为制造强国战略、战略性新兴产业、绿色制造战略研究; E-mail: 1p@cae.cn 基金项目：中国工程院重大咨询项目 “‘十三五”战略性新兴产业培育与发展规划研究”(2014-ZD-7)

本刊网址：www.enginsci.cn 
要走一条绿色发展道路。党的十八大提出, 大力推 进生态文明建设, 着力推进绿色发展、循环发展、 低碳发展, 这是中国实现社会主义现代化的一个根 本任务和基本途径, 也是中国进入经济发展新常态 实现产业转型升级的重要方向和关键内容。

实现绿色发展, 首先要依靠科学技术创新实现 节能减排, 其次还要执行最严格的环境保护政策。 中国目前的能源消耗高, 能效很低, 节能拥有巨大 的空间。2014 年, 中国单位国内生产总值（单位 GDP ) 能耗是世界平均水平的 2.14 倍, 日本的 4.56 倍。如果通过提高能效, 将单位 GDP 能耗降到世 界平均水平, 在不增加能源消耗条件下, 中国 GDP 可以再翻一番; 如果降到日本目前水平, 中国 GDP 可以再翻两番 ${ }^{[1]}$ 。因此, 节约能源是中国绿色发展 战略规划的重要目标之一, 重点瞄准制造业节约成 本和提高能效。

节能对于中国能源危机具有重要的战略意义, 因为制造业的能源消耗大概占到中国能源消耗的 $56 \%$ 以上 ${ }^{[2]}$ 。特别是提升制造业装备（例如电机） 绿色化水平，包括促进大范围绿色制造技术扩散， 最终使量大、面广的生产设备降低能耗。节能是一 项公共治理特征明显的工作, 单纯依靠市场无法奏 效, 需要政府积极干预。制造业装备节能与普通节 能项目不同，普通节能项目中地方政府动力不足。 针对制造业升级节能来说, 涉及到制造业竞争力和 地区经济的提升, 地方政府及企业都有积极性。但 是, 由于涉及到高新技术创新和推广, 并且存在着 大量技术和市场的不确定性, 仍然需要政府的积极 干预才能推进节能项目。在传统节能模式中, 自 上而下 (强制命令) 的节能目标责任制发挥了重要 作用, 解决了地方政府的积极性问题, 也通过监控 (中央、省属、市属等) 节能重点企业来达到部分 节能目标 ${ }^{[3]}$ 。但是, 节能目标责任制执行成本高, 而且地方政府、企业缺乏主动性, 尤其是当制造 业节能工作从 “节能重点企业” 拓展到更广泛的 制造业中小企业的时候, 实施自上而下的政策遇 到很大的困难。更好地引入并发挥市场机制的作 用，提高政策执行效率，充分利用政策调动制造 业企业节能的积极性, 是制造业节能升级改造面 临的核心问题。

本文通过案例研究来探索这个问题, 并通过示 范推广项目有效地促进绿色制造技术在制造业企业
的扩散。研究问题包括：电机能效提升面临的困难 是什么? 地方政府解决电机能效提升困难的政策和 措施是什么? 这些政策和措施对未来中国政府的节 能治理有什么借鉴意义?

\section{二、障碍：绿色制造技术扩散障碍分析}

一般示范推广项目可以加速工业创新的进程, 通过测试和降低技术不确定性来突破技术障碍, 支 持战略性新兴产业发展。周源等 ${ }^{[4]}$ 研究显示, 绿色 技术扩散的大部分研究集中在创新体系中的示范推 广项目, 特别是在生态可持续性转型和新能源技术 发展方面受到强烈关注。但是很少有人关注主流制 造业的绿色技术创新, 尤其是在发展中国家的经 济领域。

绿色制造技术扩散的障碍可以分成三类：技 术障碍、非技术障碍和采用绿色技术的特殊障碍。 其中, 主要的技术障碍包括: 定性分析对技术先 进性、安全性、可靠性、操作性、适用性和节能 技术兼容性的疑虑 ${ }^{[5]}$ 。绿色技术的非技术障碍包 括：信息不对称, 缺少公众标准和专业认证的信 心，不确定的投资回款周期，有限的融资渠道和 额外增加的成本费用, 不满意的基础建设、设备 提供者和渠道, 无法控制的维修费用、维护服务, 含糊不清或者过于严格的管理条例, 以及各种利 益相关者的利益冲突。特别是, 对于中小企业来说, 更愿意投资在扩大再生产而不愿意投资在低优先 权的节能项目上，对节能管理的投入则更少，并 且很少采用绿色技术 ${ }^{[6]}$ 。通常, 绿色制造示范项 目需要一系列的政策工具 ${ }^{[7]}$, 为了应对多方面的障 碍, 政策工具组合被认为是有效手段 ${ }^{[8]}$ 。然而, 政 策组合工具模型需要明确的目标和政策框架。本 研究遵循 “技术推动” 和 “需求拉动” 的政策框架。 “技术推动” 政策包括政府资助的研发创新、学习 先进技术、教育和培训等; “需求拉动” 政策可以 提高收益, 促进创新, 例如: 知识产权保护、减 免税收和顾客购买新技术退税等 ${ }^{[9]}$ 。上述文献研 究表明, 政策工具组合有技术测试认证、促进信 息交流学习和降低经济风险的效果。本文通过全 国电机能效提升项目中各地方政府的典型做法和 东莞市的金融创新模式，探索克服绿色制造技术 扩散障碍的政策框架和政策工具组合。 


\section{三、政策：中国电机能效提升项目政策类型 分析}

电机广泛应用于治金、石化、煤炭、建材、造 纸等多个行业和领域。据统计测算, 目前我国电机 保有量约 $1.7 \times 10^{9} \mathrm{~kW}$, 总耗电量约 $3 \times 10^{12} \mathrm{~kW} \cdot \mathrm{h}$, 占全社会总用电量的 $64 \%$, 其中工业领域电机总 用电量为 $2.6 \times 10^{12} \mathrm{~kW} \cdot \mathrm{h}$, 占工业用电的 $75 \%{ }^{[10]}$ 。 为了进一步提高中国的电机效率，2013 年 6 月 28 日,工业和信息化部和国家质检总局联合印发了《电

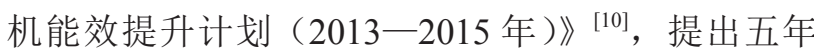
内实现电机产品升级换代目标：累计推广高效电机 $1.7 \times 10^{8} \mathrm{~kW}$, 淘汰在用低效电机 $1.6 \times 10^{8} \mathrm{~kW}$, 实 施电机系统节能技术改造 $1 \times 10^{8} \mathrm{~kW}$ ，实施淘汰电 机高效再制造 $2 \times 10^{7} \mathrm{~kW}$ 。结合国家出台的电机能 效提升计划及淘汰路线图, 各地方省市出台了配套 的政策措施和做法, 中国电机能效提升政策类型如 表 1 所示。

\section{(一) 行政命令型}

政府通过国家行政命令，强制淘汰落后产能 是实现电机能效提升项目的有力保障。以高耗能 产业为代表的重工业，如钢铁、化工、水泥等企 业的能源成本占其总成本的 $70 \%$ 以上 ${ }^{[3]}$ 。这些重 工业部门除了依靠技术进步之外，在很大程度上 还依靠淘汰落后产能。国家以目标责任制的方式 加强淘汰落后产能的执行力度。例如, 工业和信 息化部发布的《高耗能落后机电设备产品淘汰目 录》是淘汰落后设备执法的主要依据。行政命令 型政策具有强制性的特点, 在强制性政策措施的 保障下，淘汰落后产能成效显著。然而，由于大 量淘汰产能被 “以小换大”（大企业换成了中小企 业)，政府对中小企业实施节能监管强制性政策的 难度和成本大大增加, 需要运用更多的市场化手 段激励、监督和引导企业节能。

\section{（二）能力建设型}

能力建设型政策帮助企业了解并采纳先进绿色 制造技术, 挖掘企业节能潜力, 提升企业的能源管 理能力。能力建设型政策的特点是政府引导, 企业 自行投入, 市场化运作。能力建设类政策的重心主 要放在提高企业节能技术和管理水平上, 但是缺 乏适当的政策工具应对企业面临的技术风险和资 金风险。

\section{（三）经济激励型}

经济激励型政策主要包括节能补贴和投融资政 策。例如, 资金补助、以奖代补、贴息和据实结算 等方式, 其特点是发挥市场机制的作用, 通过补贴 政策提高节能政策执行效率, 充分动员政策执行中 介（节能服务公司）的主动性，做大节能市场。节 能补贴政策可以帮助企业摆脱节能升级改造融资难 的困境。但是, 从长远看, 节能减排单靠政府补贴 是不可持续的, 最终还是要依靠市场的力量促进行 业发展, 倒逼企业转型升级, 否则企业容易依赖补 贴, 一旦取消补贴, 考验的是用电企业的技术实力。 所以要实现工业可持续发展, 最终还是要靠企业的 技术创新，拉动产品能效，降低制造成本。

在上述传统的绿色制造技术推广政策模式中, 行政命令型政策需要政府强力介入大企业。然而, 当面对量大面广的中小企业时, 节能目标责任制执 行成本高, 政府需要通过经济激励政策调动市场资 源, 做大节能市场。单纯依靠节能补贴政策是不可 持续的, 还要依靠能力建设。最终, 企业依靠技术 推动实现制造业绿色可持续发展。

开展电机能效提升综合示范项目, 是以点带面 推进节能减排的重要途径, 是激励地方开展制度创 新的重要手段, 具有十分重要的意义。把行政命令 型、经济激励型和能力建设型政策组合起来, 强制 淘汰落后产能, 发挥市场调节作用, 技术创新推动

表 1 中国电机能效提升政策类型

\begin{tabular}{ccccc}
\hline 类型 & 手段 & 特点 & 优势 & 不足 \\
\hline 行政命令型 & 淘汰落后产能 & 强制性 & 调动政府积极性 & 执行成本高 \\
& 节能目标责任制 & 自上而下 & 对大企业有效 & 对中小企业无效 \\
能力建设型 & 信息引导 & 示范推广 & 技术推动 & 技术风险 \\
& 技术推广 & 自下而上 & 提高企业竞争力 & 资金风险 \\
经济激励型 & 节能补贴 & 资金引导 & 解决融资难题 & 财政资金有限 \\
& 投融资政策 & 市场化运作 & 扩大节能市场 & 补贴不可持续 \\
\hline
\end{tabular}


节能减排工作。地方政府需要打好政策组合拳, 综 合运用法律、行政、经济、技术等手段，制定产业、 财政、税收、金融等政策，发挥好政府对节能企业 的引导作用，充分激发节能减排的内生动力。

\section{四、典范：东莞市电机能效提升政策创新 分析}

东莞市是制造业名城, 也是广东省第一用电大 市。东莞市政府以 “万台注塑机伺服节能改造” 作 为绿色制造示范推广项目, 组合各地方节能政策, 同时主要通过能力建设型政策和金融创新确保电机 能效提升工作高水平推进。

\section{（一）东莞市工业和电机行业用电现状}

2013 年，东莞市全社会年用电超过 $6 \times 10^{10} \mathrm{~kW} \cdot \mathrm{h}$, 其中工业用电超过 $4.5 \times 10^{10} \mathrm{~kW} \cdot \mathrm{h}$, 用电量长期位 居广东省首位。“十一五” 以来, 东莞市工业用电 量年均增幅 $3.77 \%$ ，同口径工业增加值增速为年均 $9.56 \%$, 比用电增幅快 $5.79 \%$, 工业用电效率提升 明显。但是, 东莞市万元 GDP 电耗水平依然较高, 2013 年超过 $1200 \mathrm{~kW} \cdot \mathrm{h} /$ 万元, 排在广东省前列, 见图 $1^{[11]}$ 。

2014 年 1 月, 东莞市能源行业协会开展电机能 效提升调研报告抽样数据显示：全市 653 个重点用 电企业在用电机总容量约为 $5.12 \times 10^{6} \mathrm{~kW} ; 2012$ 年 企业总耗电量为 $1.99 \times 10^{10} \mathrm{~kW} \cdot \mathrm{h}$, 约占全市工业用 电量 $\left(4.4293 \times 10^{10} \mathrm{~kW} \cdot \mathrm{h}\right)$ 的 $45 \%$ 。造纸及纸制 品行业是东莞市的电机能耗第一大户, 占全市工业 用电量的 $44.73 \%$, 见图 2 。

\section{（二）东莞市电机节能面临的难题}

东莞市工业企业在电机能效提升方面面临三 大难题：节能意识较差、技术人才缺乏、资金压 力大。东莞市的电机用户多是中小企业, 之前没有 接触过电机节能的相关项目, 对于电机节能的认识 不足。由于电机主要应用于主生产线或关键工序, 用户担心因电机节能改造影响正常生产, 带来质 量、安全等方面的问题, 因此不愿意在电机节能 方面投入资源。此外，大多数企业缺乏专业的技 术改造人才, 自身实施节能改造难度大。实施电 机能效提升项目的另一大困难则是资金压力，尤其 是近年来受经济下行和市场需求双重疲软的影响, 企业主动进行节能技术改造的积极性不高。最后, 电机能效提升还缺乏政策层面的支持。尽管政府的 节能监察任务中包涵淘汰落后电机，但是对于注塑 机小型电机改造缺乏明确的政策依据, 完全依靠企 业自主进行。

\section{（三）东莞市政府的电机能效提升政策体系和模式 创新}

2013 年以来, 东莞市针对电机能效提升所面临 的困难,制定了组合政策工具和一系列推广措施 (见 表 2), 主要包括: 2013 年 6 月, 东莞市开展全市 注塑机存量调查; 2013 年 7 月底, 下发《东莞市万 台注塑机伺服节能改造试点实施方案》; 2013 年 10 月, 遴选节能服务公司, 并将节能改造任务细化下 达; 2013 年 12 月, 发布补贴实施细则; 2014 年 7 月, 启动补贴网上申报系统; 2014 年 11 月, 发布《关 于促进节能服务与金融产业融合加快推进节能减排 典型示范项目建设工作方案》。该方案构建引入银

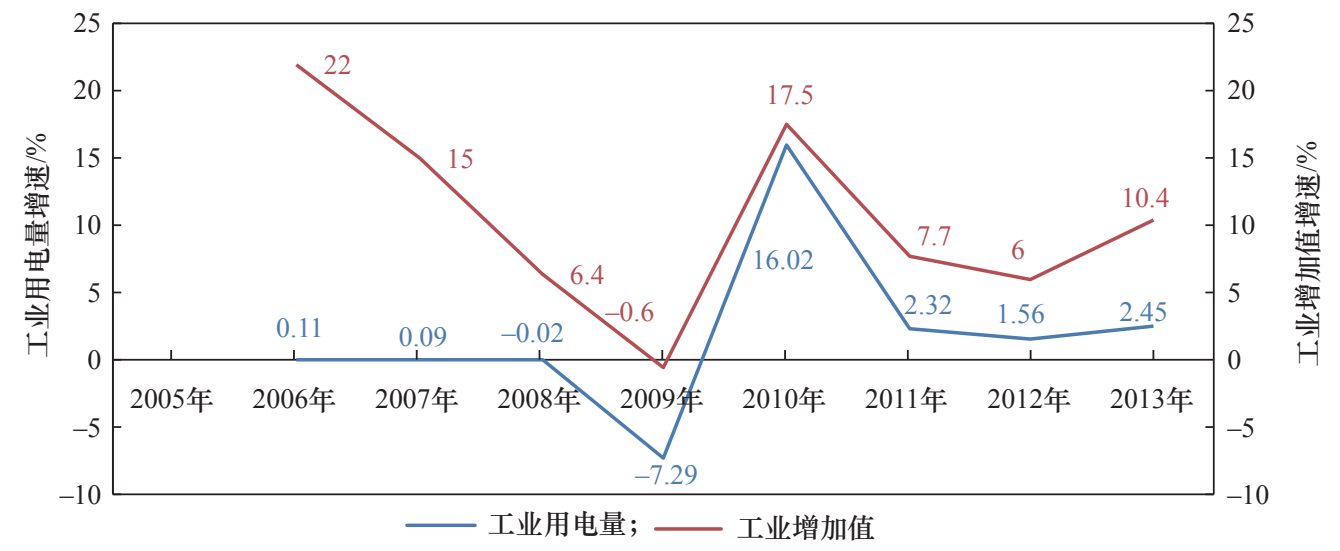

图 1 东莞市工业用电量和工业增加值增速（2005-2013） 


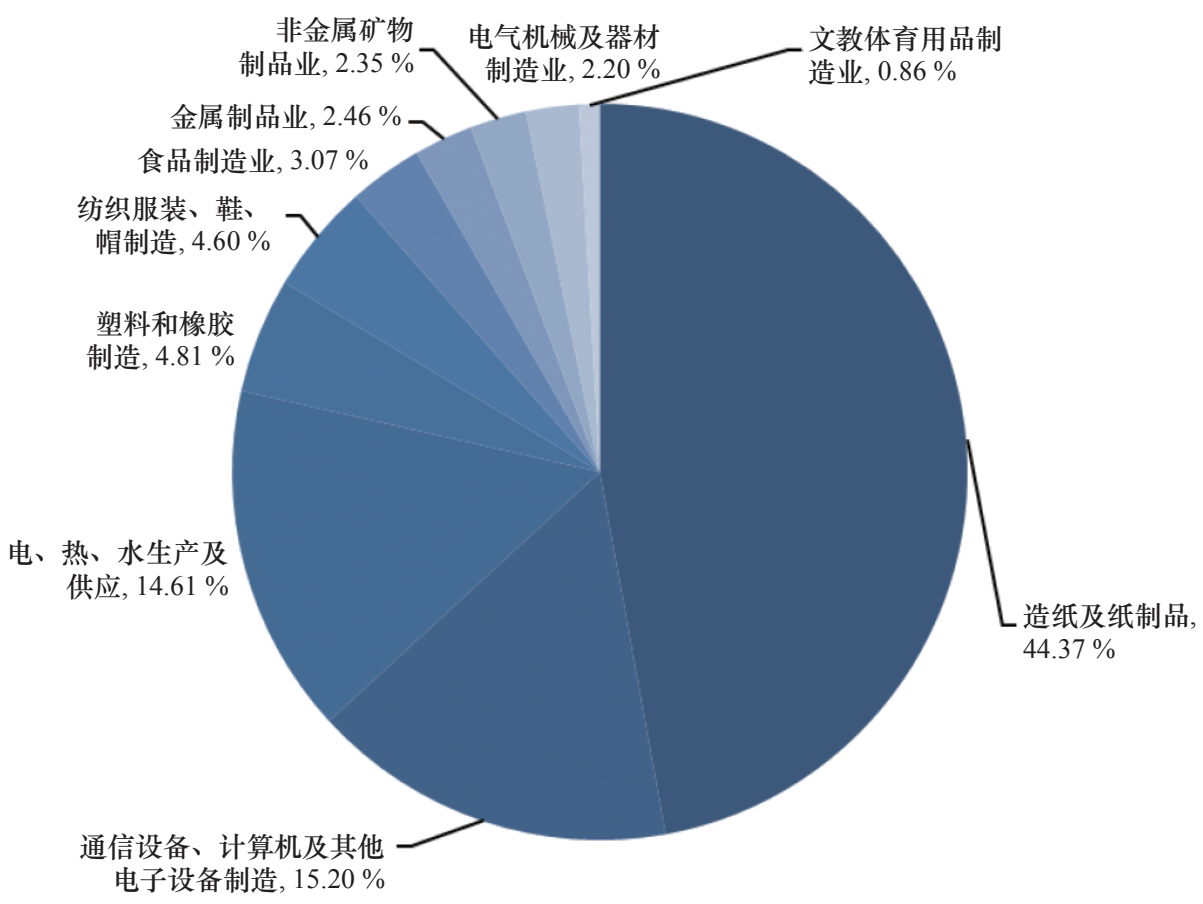

图 2 东莞市在用电机行业分布情况

表 2 东莞市注塑机电机能效提升项目的主要政策和推广措施 ${ }^{[12]}$

\begin{tabular}{|c|c|}
\hline 时间 & 东莞市注塑机电机能效提升项目的主要政策和推广措施 \\
\hline 2013 年 1 - 3 月 & 在旭和电器厂试点改造两台注塑机 \\
\hline 2013 年 5 月 & 旭和电器厂与东莞华数节能公司开展合作, 首期完成 10 台注塑机伺服节能升级改造 \\
\hline 2013 年 6 月 & 东莞市进行项目预调研，大概有 2 万台注塑机需要节能升级改造 \\
\hline 2013 年 7 月 & $\begin{array}{l}\text { 东莞市政府印发《东莞市万台注塑机伺服节能改造试点实施方案》, 包括补贴政策（最大补贴额度 } \\
200 \text { 元 } / \mathrm{kW} \cdot \mathrm{h}, \text { 大概占节能改造成本的 } 10 \% \sim 15 \%)\end{array}$ \\
\hline 2013 年 8 月 & 东莞认定了五家节能服务公司注塑机伺服节能改造的资质 \\
\hline 2013 年 8 - 12 月 & 镇街额外补贴 （50 100 元 /kW·h） \\
\hline 2013 年 $7-12$ 月 & 当地政府组织信息交流会（包括学术论坛、网络调查、官方推荐和检查） \\
\hline 2014 年 1 月 & 东莞市进行项目中期评估（638 家企业）, 确认大多数公司了解电机能效提升项目 \\
\hline 2014 年 5 月 & 当地政府向工信部汇报电机能效提升项目的进程 \\
\hline 2014 年 7 月 & 启动补贴网上申报系统 \\
\hline 2014 年 11 月 & 东莞市发布《关于促进节能服务与金融产业融合加快推进节能减排典型示范项目建设工作方案》 \\
\hline
\end{tabular}

行作为第三方担保的节能改造新模式，主要实施措 施如下。

1. 引入金融信用担保模式破解融资难题（见 图 3)

用能单位根据节能服务公司出具的担保函, 从 银行贷款进行电机节能升级改造。担保函保障银行 给用能单位贷款，产生了稳定的现金流，同时保障 节能服务公司能够拿到合同能源管理的回款。政府 把补贴真正给节能用户单位, 银行也从中扩大客户 群，增加存款。最终，政府通过补贴和金融手段平
衡各方利益, 促进推广高效电机节能项目。

2. 推广融资租赁模式破除金融风险（见图 4)

政府按金融机构执行合作计划及完成情况, 分 期以定期存款方式存入试点金融机构专户。试点金 融机构按照不低于风险补偿资金池 10 倍的规模进 行信贷放大, 对电机能效提升的合同能源管理项目 提供金融支持。因实施电机节能项目开立支付保函 产生风险损失的，市财政在不超过每个金融机构实 际开出保函总额的 $10 \%$ 限额内, 给予风险损失补 偿; 风险损失总额超过 $10 \%$ 限额的超出部分由相 
应金融机构自行承担。

3. 建立第三方机构核查制度保障项目实施效果 政府通过公开甄选, 委托第三方机构开展核 查, 解决节能效果认定问题。东莞市经济和信息化 局通过招标方式, 公开遴选专业第三方节能量审核 机构, 并委托第三方对电机能效提升项目的节能效 果进行评价, 出具专业核查报告, 并作为评定项目 节能效果和申请补贴的主要依据。根据第三方核查 报告, 在项目实施完工和节能效果满足合同约定的 条件下，金融机构才向节能技术服务单位提供不可 撤销的支付保函。东莞市经信局负责第三方核查机 构的审核工作并进行监管。
（四）东莞市电机能效提升政策小结

东莞市制定了行政命令型、能力建设型、经济 激励型政策工具组合和金融模式创新, 解决了电机 能效提升面临的难题。

\section{1. 行政命令型}

东莞市各镇 (街) 与用电企业签订电机能效提 升目标责任书, 将电机能效提升目标完成情况作为 企业节能目标考核的重要内容; 东莞市严格执行强 制性电机能效标准, 加大落后电机设备检查淘汰力 度, 严禁企业采用国家明令淘汰的落后电机。网上 申报系统实时监管申报企业淘汰落后旧电机情况, 降低了电机节能政策的执行成本。

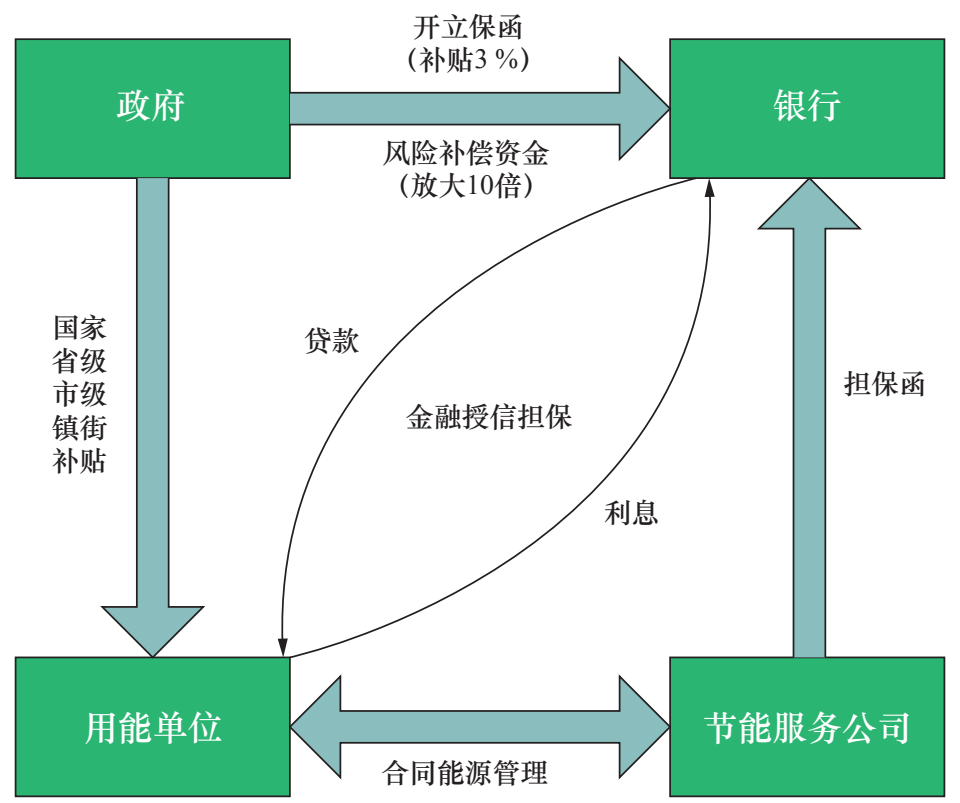

图 3 东莞市政府采用的金融信用担保模式框图

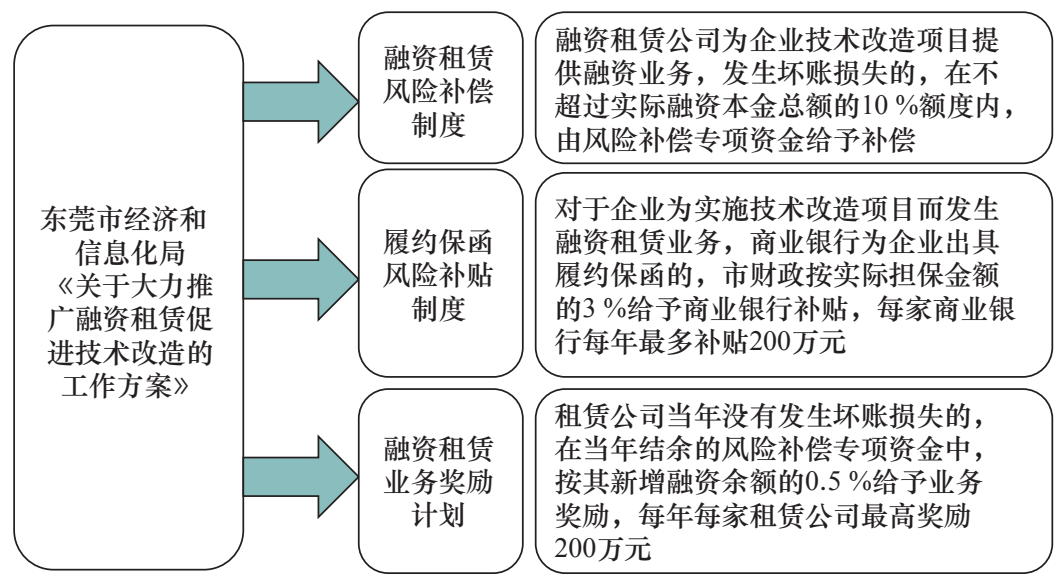

图 4 东莞市政府推广融资租赁模式工作方案和具体措施 


\section{2. 能力建设型}

东莞市召开现场示范技术推广会, 帮助企业了 解电机节能技术。东莞市举办电机能效提升核查工 作培训班，培训有关单位的节能工作人员，培训内 容包括电机基本知识、电机节能政策和第三方核查 程序等。举办技术推广会和培训班, 解决技术认证 和信息学习的问题。能力建设型政策突出企业引领 作用, 发挥典型示范作用, 以点带面, 促进绿色制 造技术在中小企业进行扩散。

\section{3. 经济激励型}

东莞市落实电机能效提升及注塑机伺服节能改 造专项资金, 首批奖励计划惠及 44 个项目, 包括 23 个电机系统改造项目, 20 个注塑机伺服节能改 造示范项目, 以及一个更换高效电机项目, 共获得 2060 万元的奖励资金。东莞市政府通过金融授信 担保政策，把风险补偿资金扩大了 10 倍，利用少 量的财政资本㧼动了大量的金融资本，解决了企 业电机节能升级改造融资难和贷款需要信用担保 的难题。

\section{4. 金融模式创新}

东莞市提出了促进节能、产业和金融 “三融合” 的创新模式, 助力企业节能升级改造。这一新模式 促进了节能服务产业与金融产业融合，加强了合同 能源管理的诚信监管体系, 一方面有助于消除节能 服务公司对用能单位能否如期分享节能效益的顾 虑, 另一方面有助于消除用能单位对节能服务机构 的技术能力以及项目改造效果的疑虑。通过金融模 式创新, 东莞市解决了企业电机节能改造的技术风 险和资金风险的顾虑问题，为其他城市探索节能市 场化模式提供了示范经验。

\section{五、结语}

本文总结了中国电机能效提升项目的典型政策 模式, 包括行政命令型、能力建设型和经济激励型 政策。基于东莞万台注塑机电机能效提升示范项目 这个案例, 揭示了利用示范推广项目促进绿色制造 技术扩散, 利用政策工具组合和模式创新来解决具 体的扩散障碍。本文的案例研究有助于探索中国可 持续发展和创新发展的新模式。

这些政策组合工具不同于传统的示范政策, 表 现在以下几个方面: 第一, 绿色制造示范项目可能
会面临各种问题，更多的是市场导向和市场经济问 题, 特别是面临对成本收益特别敏感的大规模技术 扩散涉及大量中小企业的问题。第二, 政府要解决 这些问题, 更多地需要考虑 “需求拉动” 政策。此 外, 还需要考虑非行政命令、市场化的政策执行者。 例如, 节能服务公司能更有效满足用电企业对于节 能服务的需求。第三, 示范推广项目往往是复杂的, 不能单独依靠某项政策来解决问题, 需要创新型的 政策。

中国的创新政策也有一些特殊性。第一，中国 正在经历由行政治理模式向市场调控模式的转变, 以市场为导向, 顶层设计政策框架和政策工具组合 受到更多的关注。在这种情况下，东莞市政府认识 到, 传统的强制性政策不能调动市场的资源, 所以 探索利用非行政命令的利益相关者（例如节能服务 公司等）实现利益共享模式。第二, 中国正在由高 速增长转向中等适度的可持续发展, 政策制定者需 要更多的耐心促进技术发展, 以减少市场不确定性, 增强潜在用户的信心。然而, 新的政策模式仍需要 中国政府的强制力来保障加速追赶转型的进程。第 三, 现有的先进技术和经济条件是非常重要的, 可 促进绿色制造技术在企业中的扩散。许多示范项目 的经验表明绿色制造技术的成功扩散离不开企业低 成本的本地技术和稳定良好的现金流，中国不能减 少对技术创新和发展经济方面的努力。

本文的研究还有一些局限性, 目前只是一个探 索和试点研究, 总结了一个政策工具组合的框架, 下一步还需要通过更多的案例研究使得政策框架更 加完善。另外, 充分评估政策措施还需要时间, 所 以未来对电机能效政策评估方面还有待继续研究。 最后，这个政策框架研究集中在政府推广示范项目 上，下一步从研究机构、行业协会和竞争者角度出 发, 进行比较研究将会更有意义。

\section{参考文献}

[1] 周济. 走绿色发展之路必须依靠科技创新[J]. 农村工作通讯， 2015(7): 39 .

Zhou J. The road to green development must rely on science and technology innovation $[\mathrm{J}]$. Newsletter about work in rural areas, 2015(7): 39.

[2] 刘雅璐. 低碳经济下我国制造业发展现状及对策研究 [J]. 改革 与战略, 2012, 28(2): 129-131.

Liu Y L. Development situation and countermeasures study of China's manufacturing industry under the low carbon econo- 
my background [J]. Reformation \& Strategy, 2012, 28(2): 129131.

[3] 齐晔. 低碳发展蓝皮书一中国低碳发展报告(2014) [M]. 北京: 社会科学文献出版社, 2014.

Qi Y. The blue book of low carbon development-Annual review of low-carbon development in China (2014) [M]. Beijing: Social Sciences Academic Press, 2014.

[4] Zhou Y, Zhang H W, Ding M Y. How public demonstration projects affect the emergence of new industries: An empirical study of electric vehicles in China [J]. Innovation Management Policy \& Practice, 2015, 17(2): 1-23.

[5] Macey S M, Brown M A. Demonstrations as a policy instrument with energy technology examples [J]. Science Communication, 1990, 11(3): 219-236.

[6] Trianni A, Cagno E, Worrell E. Innovation and adoption of energy efficient technologies: An exploratory analysis of Italian primary metal manufacturing SMEs [J]. Energy Policy, 2013, 61: 430-440.

[7] Hendry C, Harborne P, Brown J. So what do innovating companies really get from publicly funded demonstration projects and trials? Innovation lessons from solar photovoltaics and wind [J]. Energy Policy, 2010, 38(8): 4507-4519.

[8] Parker C M, Redmond J, Simpson M. A review of interventions to encourage SMEs to make environmental improvements [J].
Environment and Planning C: Government \& Policy, 2009, 27(2): 279-301.

[9] Nemet G F. Demand-pull, technology-push, and government-led incentives for non-incremental technical change [J]. Research Policy, 2009, 38(5): 700-709.

[10] 中华人民共和国工业和信息化部, 国家质量监督检验检疫总局. 电机能效提升计划(2013-2015 年) [EB/OL]. (2013-06-21) [201605-12]. http://www.miit.gov.cn/n1146295/n1652858/n1652930/ n3757016/c3761920/content.html.

Ministry of Industry and Information Technology of the People's Pepublic of China, General Administration of Quality Supervision of the People's republic of China. National project on energy saving through upgrading electric motors (2013-2015) [EB/OL]. (2013-06-21) [2016-05-12]. http://www.miit.gov.cn/n1146295/ n1652858/n1652930/n3757016/c3761920/content.html.

[11] 东莞市统计局, 国家统计局东莞调查队. 东莞市统计年鉴(2014) [M]. 北京: 中国统计出版社, 2014.

Dongguan Bureau of Statistics, Dongguan Survey Team from National Bureau of Statistics. Dongguan statistical yearbook 2014 [M]. Beijing: China Statistics Press, 2014.

[12] Zhou Y, Xu G N, Tim M, et al. How do public demonstration projects promote green-manufacturing technologies? A case study in China [J]. Sustainable Development, 2015, 23(4): 217-231. 